\title{
Dinâmicas urbanas em espaços sertanejos piauienses: Riscos e vulnerabilidades sócioambientais em Picos/PI
}

\author{
Dinámica urbana en espacios sertanejos de Piauí (DUESPI): riesgos y vulnerabilidades \\ socio-ambientales en Picos/PI
}

Juscelino Gomes Lima'

\section{Resumo}

As rápidas e acumuladas transformações ocorridas no interior das cidades brasileiras, notadamente, as nordestinas e, em particular apreço, as piauienses, vêm sinalizando inúmeros rebatimentos na qualidade e nas condições de vida das populações residentes. Nesse sentido, apresenta-se a cidade de Picos/PI. Uma urbe de expressividade, importância e comando regional que tem experimentado amplas mudanças em sua tessitura urbana, provocando cenários de riscos e vulnerabilidades socioambientais. Dessa forma, o presente artigo busca analisar e descrever a produção de riscos e vulnerabilidades socioambientais, a partir das transformações urbanas locais, notadamente, a promovida pelo vetor imobiliário. Nesse encaminhamento, alimenta-se uma proposta conceitual que é de DINÂMICAS URBANAS EM ESPAÇOS SERTANEJOS PIAUIENSES (DUESPI) a qual objetiva compreender e explicar as transformações em tela, bem como os fatores indutores para tais. Como resultado, observou-se que a cidade cresce e transforma-se sem perspectivas de planejamento urbano e ações de políticas públicas para tal. As áreas de expansão, por um lado, coincidem com o acúmulo da pobreza, desigualdades e ausência de infraestruturas; por outro, são alvos das práticas de especulação imobiliária que tomam os melhores espaços de crescimento da cidade para produtos imobiliários de alto valor capital. Complementa esse quadro, o aumento de problemas ambientais, onde seus elementos estão cada vez mais exauridos.

Palavras Chave: Dinâmicas Urbanas. Sertões. Riscos. Vulnerabilidades. Picos/PI.

\section{Resumen}

Los rápidos y acumulados cambios en las ciudades brasileñas que han ocurrido en el interior de las ciudades brasileñas, notoriamente, en las ciudades ubicadas a noreste del País, en particular las de Piauí, ha señalizado numerosas repercusiones en la calidad y condiciones de vida de los residentes locales.En este sentido, se presenta la ciudad de Picos/PI. Una metrópolis de expresión, importancia y comando regional que ha experimentado cambios radicales en su tejido urbano, provocando situaciones de vulnerabilidad social y ambiental. Por lo tanto, este artículo pretende analizar y describir la producción de los riesgos ambientales y las vulnerabilidades, de las transformaciones urbanas locales, especialmente los bienes inmuebles promovidos por el vector. En

1 Doutorando; Desenvolvimento Regional; Universidade de Santa Cruz do Sul, UNISC, Brasil; Estudante/Pesquisador na Universidade de Santa Cruz do Sul, UNISC, Brasil; Endereço: Instituto Federal do Piauí - IFPI, Av. Pedro Marques de Medeiros, s/n - Pantanal, Picos - PI, CEP: 64600-000 - Picos, PI - Brasil; E-mail: geocelino@hotmail.com

\begin{tabular}{llllll}
\hline Ambiência & Guarapuava (PR) & v.14n.1 & p. 85-100 & Jan/Abr 2018 & ISSN $1808-0251$
\end{tabular}


este recto, se alimenta una propuesta conceptual que es DINÁMICA URBANA EN ESPACIOS SERTANEJOS DE PIAUÍ (DUESPI) que tiene la intención de comprender y explicar los cambios en cuestión, bien como los factores que inducen a tales. Como resultado, se observó que la ciudad crece y se convierte sin planificación sin perspectivas de la planificación urbana y acciones de política pública para hacerlo. Áreas de expansión, por un lado, coinciden con la acumulación de la pobreza, la desigualdad y la falta de infraestructura, por el otro, son los objetivos por las prácticas de especulación de tierras que hacen mejores zonas de crecimiento de la ciudad para los productos inmobiliarios de capital de alto valor. Complementar a esta situación, hay el aumento de los problemas ambientales, donde sus elementos han empobrecido cada vez más.

Palabras clave: Dinámica urbana. Tierras del Agreste. Riesgos. Vulnerabilidades. Picos/PI.

\section{Introdução}

No Brasil, o fenômeno da urbanização ganha corpo a partir do início do século XX, com destaque influenciador para o processo de industrialização, que se fez primeiro e, necessariamente, na Região Sudeste, de forma rápida, concentrada e segregadora, produzindo profundas mudanças, não apenas no que se refere ao perfil demográfico, mas, sobretudo, com relação aos aspectos econômicos, sociais e ambientais, repercutindo a partir dos anos 1970, nas demais regiões brasileiras, entre elas, a Região Nordeste.

Dessa repercussão, assiste-se desde então, paulatino e gradativamente, além das mudanças nos aspectos mencionados, também a reprodução de condições, dantes exclusivas dos grandes centros metropolitanos, via descentralização produtiva/econômica pelo território nacional, notadamente no caso do Nordeste brasileiro, esse fenômeno encontrou base, principalmente, por meio de uma "integração da estrutura produtiva inter-regional, mediante a transferência de capitais - sob a égide do Estado" (ARAUJO, 1997, p. 55).

Nesse contexto, estabeleceram-se novas articulações com os processos e com a dinâmica de desconcentração produtiva/econômica em tela, resultando sobre esta região, uma série de transformações que vem ensejando um quadro de superações de letargia e atrasos, com destaque sobre cidades sertanejas, notadamente, as piauienses. Destas, toma-se como objeto de análise, a cidade de Picos/PI que, dada sua estratégica localização regional e sua importância como centro dinâmico e de comando comercial e de serviços para todos os municípios que compõem o Território de Desenvolvimento do Vale do Rio Guaribas ${ }^{1}$ marca-se por sua "força econômica e a extensiva cobertura de serviços públicos que servem a um conjunto de população" (FILHO, 2004, p. 120).

A dinamicidade em questão se faz permitida por uma série de elementos e variáveis ${ }^{2}$ a serem identificadas por esta pesquisa que alimenta um dos objetivos a serem propostos: a composição de um conceito - Dinâmicas Urbanas em Espaços Sertanejos Piauienses (DUESPI). Dessa forma, o presente artigo busca analisar e descrever a produção de riscos e vulnerabilidades socioambientais,

Compõem-se de 39 municípios, totalizando um total de 345.144 habitantes, equivalendo a 10,97\% da população total do Estado do Piauí. A extensão de sua área total é de $22.727,04 \mathrm{Km}^{2}$, representando aproximadamente $9,03 \%$ do território total do Estado. Esta composição é registrada no Plano Territorial de Desenvolvimento Rural Sustentável - PTDRS, resultante do processo participativo de planejamento do desenvolvimento do Estado do Piaú. Tal plano é resultado de trabalho do Ministério do Desenvolvimento Agrário, por meio da Secretaria de Desenvolvimento Territorial. 
a partir das transformações urbanas locais, notadamente, a promovida pelo vetor imobiliário. Nesse encaminhamento, alimenta-se uma proposta conceitual que é de DINÂMICAS URBANAS EM ESPAÇOS SERTANEJOS PIAUIENSES (DUESPI) que tenciona compreender e explicar as transformações em tela, bem como os fatores indutores para tais.

Como resultado, observou-se que a cidade cresce e transforma-se sem perspectivas de planejamento urbano e ações de políticas públicas para tal. As áreas de expansão, por um lado, coincidem com o acúmulo da pobreza, desigualdades e ausência de infraestruturas, por outro, são alvos das práticas de especulação imobiliária que tomam os melhores espaços de crescimento da cidade para produtos imobiliários de alto valor capital. Complemente esse quadro, o aumento de problemas ambientais, onde seus elementos estão cada vez mais exauridos.

O artigo é constituído de três seções: (i): Cidades, riscos e vulnerabilidades: uma revisão necessária; (ii) Dinâmicas Urbanas em Espaços Sertanejos Piauienses (DUESPI): transformações em Picos/PI; (iii) Considerações finais. Finaliza a composição, a listagem das referências bibliográficas.

Na primeira seção são discutidas os fatos e questões envolvidos para a promoção dos cenários de riscos e vulnerabilidades socioambientais, marcando decisivo e dialeticamente a morfologia das cidades. Já na segunda seção, é discutido o frenesi de transformações na cidade de Picos, ocasião em que se faz proposto o aludido conceito, como forma de suporte compreensivo às transformações em sua forma urbana, destacando o vetor imobiliário para tal e assim, a ciranda de consequências.

Material e Métodos

$\mathrm{O}$ arcabouço metodológico parte do entendimento acerca da construção heterogênea e complexa do que é a cidade, momento apoiado no método materialista histórico e dialético. A condição do materialismo justifica-se pela necessidade de compreensão mais ampliada das questões marcantes que se destacam sobre a formação/organização da referida urbe sertaneja piauiense.

Desse fato, encontra-se em Santos (2008) uma plausível justificativa para o uso de tal recorte metodológico, pois o mesmo pondera que não há como discutir uma teoria da espacialidade sem identificar e analisar as formações sociais, sendo necessário o estudo da formação do espaço, sobretudo após a "chegada do modo de produção capitalista".

Já com a dialética, buscar-se-ão os determinantes das condições de organização e contradições espaciais, resultantes da dinâmica em exposição, oportunidade que permite enxergar que "sujeito e objeto são intrínsecos; o sujeito se constrói e se transforma, construindo e transformando, ao mesmo tempo, o objeto, que construído (fruto do trabalho humano) influencia as ações do sujeito" (SALVADOR, 2012, p. 101).

Associado a esta escolha fez-se uso pesquisa de campo (in lócu), com aplicação de entrevistas semiestruturadas em roteiros pré-estabelecidos. Para a constituição do conceito em apreço, tomou-se como referência, trabalho dissertativo encabeçado por Lima (2014). A pertinência da discussão sobre riscos e vulnerabilidades socioambientais é baseada em Aquino e Veloso Filho (2000); Bonametti (2010); Santos (2008), Zanella et al (2009), entre outros.

Estes impulsionam novas condições produtivas/econômicas na cidade de Picos, marcando-a como uma urbe de forte comando regional no centro sul do estado do Piaú, reproduzindo, entre várias possibilidades, novas formas urbanas, quer seja pela abertura de novas vias de circulação, empreendimentos, construções, ou seja, diferentes conteúdos técnicos, via fixos e fluxos que entre outros rebatimentos, materializam e encarecem cada vez mais o preço de parcelas do solo urbano, dificultando o seu acesso por diferentes grupos sociais e dessa forma, além de uma continua transformação paisagística e produção de vulnerabilidades socioambientais. A referida identificação toma por base/modelo de discussão e quadro empírico de referência Dissertação de Mestrado de Lima (2014). 


\section{Resultados e Discussão}

Produção das cidades, riscos e vulnerabilidades: uma revisão necessária

O aumento progressivo da população urbana tem contribuído vertiginosamente para uma série de transformações, quer seja nos conteúdos ambientais ainda restantes, quer seja, sobre suas paisagens com sérios rebatimentos os quais tendem à produção de vulnerabilidades socioambientais. Estas decorrem de "uma miríade de fatores que tornam os grupos mais ou menos suscetíveis aos impactos derivados de riscos diversos, que se formam nos contextos urbanos" (MENDONÇA; LEITÃO, 2008, p. 149). Falar dessas vulnerabilidades significa provocar olhares também sobre a noção de riscos, já que o "conceito de vulnerabilidade é absolutamente indissociável do conceito de risco" (REBELO, 2010).

A indissociabilidade nos força conhecer que o cerne de sua abrangência de compreensão perpassa pelo crivo discutivo das ciências da natureza, bem como das ciências sociais, conformando ai uma abordagem dual, com várias interfaces de análises do qual os "riscos urbanos como produto combinado de um "àlea” (fenômeno aleatório) e de uma vulnerabilidade" (MEDONÇA, 2005, p. 141).

Nessa possibilidade, percebe-se o correlacionamento de tais situações uma vez que afetam, "direta ou indiretamente, individual ou coletivamente, o ser humano, na sua saúde, nos seus bens ou nos modos de funcionamento das instituições em que se enquadram na economia, na sociedade e na cultura" (FREITAS; CUNHA, 2013, p. 16). Percebe-se aí que tais condições denotam prejuízos, sinônimo de percas. Quer seja de ordem natural, material e ou humana, os prejuízos em destaque revelam que a noção de risco "está ligada tanto às ciências da natureza quanto às ciências da sociedade e, respeitando-se esta dualidade e esta interface, entende-se o risco como um produto combinado: aquele de uma eventualidade e de uma vulnerabilidade" (DUBOISMAURY; CHALINE, 2004, p. 11).

As cidades brasileiras nesse contexto têm em seu histórico de organização espacial o elencar de condições que explicam e justificam a expansividade dos eventos de riscos e vulnerabilidades socioambientais, notadamente quando se leva em consideração fatores como fortes desequilíbrios regionais, "estampados na economia, e a precariedade de vida no campo levaram grandes fluxos migratórios às cidades, onde a industrialização [...] e a maior facilidade de acesso aos equipamentos das áreas urbanas sinalizavam para uma melhor qualidade de vida” (ALMEIDA, 2012, p. 08).

No entanto, a realidade edificada foi de concentração de problemas sociais, dos quais citam-se: desemprego, violências, desigualdades de várias ordens e origens, bem como déficits habitacionais e como resultante desses fatos, a expansão de áreas periféricas, deslocando essa massa de desassistidos na cidade para vazios urbanos, coincidentemente, em áreas de vulnerabilidades e riscos. Desses fatos, percebe-se o quanto se faz necessário o processo de gerenciamento das cidades, particularmente, a partir do conhecimento de suas problemáticas e realidades. Nesse ínterim, o espaço socioambiental urbano emerge como "aquele onde vive e no qual articula indissoluvelmente sociedade e meio ambiente” (GRAZIA; QUEIROZ, 2001, p. 15).

Protagonizam, aí, duas facetas opostas e dialéticas: o progresso representado pela materialidade urbana, bem como a sedução permitida em tal e o retrocesso de valores e condições humanas, além das problemáticas ambientais, tais como poluição do ar, da água e do solo 
gerados pelas indústrias e pelos automóveis, fato que amplia os problemas relacionados com a "miserabilidade da população pobre, que sobrevive em péssimas condições sanitárias, vivendo em grandes adensamentos demográficos nos morros, mangues, margens de rios, correndo riscos de toda natureza”. (ROSS, 2008, p.275).

Nesse sentido e considerando as espacialidades urbanas, com dinâmicas regidas em diferentes contextos históricos, assiste-se fortemente nesse ínterim, à produção constante de perturbações das condições ambientais, momento em que a cidade é lócus "privilegiado da vulnerabilidade, notadamente aqueles que se relacionam à ocupação de sítios susceptíveis a processos naturais perigosos e potencialmente causadores de danos e prejuízos à sociedade"(ALMEIDA, 2011, p. 75).

Pensando dessa forma, faz-se importante lembrar que as vulnerabilidades, particularmente, as socioambientais, bem como os riscos, emergem como um conjunto de condições articulados que são alimentados em função da existência de uma série de variáveis, de ordens sociais e naturais, marcando o aparecimento e "coexistência ou sobreposição espacial entre grupos muito pobres e com alta privação, ou seja, vulnerabilidade social, e áreas de risco ou degradação ambiental” (DESCHAMPS, 2004, p. 87).

A constituição dessas realidades respondem em grande parte à forte atuação do capital imobiliário, que caminha junto ao dinamismo das atividades capitalistas nas cidades, operando em condições vantajosas diante de outros setores da economia, à medida que consegue influir em (e antecipar) ganhos decorrentes dos mecanismos formadores da renda da terra, particularmente a renda diferencial (LIPIETZ, 1974; TOPALOV, 1974; BALL, 1977).

A produção dessa realidade revela que o espaço urbano é renovado em modelo capitalizado, na verdade, uma mercadoria à venda, oportunidade em que os Agentes Produtores do Espaço Urbano $^{3}$ são "dotados de interesses, estratégias e práticas espaciais próprias, portadores de contradições e geradores de conflitos entre eles mesmos e com outros segmentos da sociedade" (CORRÊA, 2012, p. 43).

\section{Dinâmicas urbanas em espaços sertanejos piauienses(DUESPI): transformações em Picos/PI}

A dinâmica de transformações sobre o solo urbano de Picos/PI é fruto da teia de condições capitais e produtivas que se processa no Brasil desde a segunda metade do século XX, período em que o Governo Federal, pela implantação de políticas visando "promover o desenvolvimento da sociedade brasileira, principalmente na política de industrialização, contribuiu para promover um maior crescimento das cidades brasileiras, com destaque para as cidades de São Paulo e Rio de Janeiro" (FAÇANHA, 1998, p. 20).

Da acumulação produtiva e econômica no Sudeste do Brasil, a partir dos anos de 1970, o Nordeste e o Piauí assistem a uma forte desconcentração econômica e produtiva que tem projetado as cidades fora do contexto metropolitano (a exemplo de Picos/PI) como importante centro urbano de articulação, comando de serviços e desenvolvimento regional assim como outras cidades de seu tamanho ${ }^{4}$.

Esse fato ocorre motivado pela busca de maior equilíbrio interurbano e urbano-regional, com vistas à "necessidade de se interromper o fluxo migratório na direção das grandes cidades e metrópoles, a busca de maior eficiência para alguns ramos produtivos [...] das políticas urbanas que

3 Estes agentes, são responsáveis direta ou indiretamente no processo de remodelação e reorganização dos espaços urbanos e dessa forma, o comando do uso e de determinação de preços dos solos urbanos. São elencados em cinco categorias: os proprietários dos meios de produção, os proprietários fundiários, os promotores imobiliários, o Estado e os grupos sociais excluídos. Maiores detalhes, ver a obra "O Espaço Urbano" (Corrêa,2002).

4 Com área de $577,304 \mathrm{~km}^{2}$, no ano de 2010, apresentou um total de 73.414 habitantes (IBGE, 2010). 
centralizavam esforços no apoio ao desenvolvimento das cidades médias brasileiras" (AMORIM FILHO; SERRA, 2001, p. 09).

O direcionamento de investimentos descentralizados no território nacional, além de uma forte reorganização socioespacial em seletivas cidades por e a partir dos diferentes agentes capitais especulativos/produtivos, vêm também permitindo um frenesi de transformações diversificados. Estas, manifestados em diversas escalas de alcance social dentro de uma mesma espacialidade intraurbana tem colaborado decisivamente para uma reconfiguração paisagística, territorial e ambiental.

Picos/PI, distante $307 \mathrm{~km}$ distante da capital Teresina, tem sua localização no centro leste do estado, na ambiência dos sertões piauienses. Dentro de seu recorte regional de localização, se por um lado, as paisagens secas e calor excessivo lhe conferem conotações imagéticas negativas, por outro lhe dão motivos para sua capacidade de comandante de uma dinâmica socioespacial forte, haja vista ser ela uma importante cidade de entroncamento rodoviário ${ }^{5}$, conectando os Estados do Piauí, Ceará e Maranhão ao resto do Nordeste e ao país, como um todo.

Associado a isso, sua potencialidade de grande produtora de mel, caju, castanha e derivados ${ }^{6}$, com importante centro de compras, comércios e serviços imprime, regionalmente, a mais de trinta municípios sua "força econômica e a extensiva cobertura de serviços públicos que servem a um conjunto de população" (FILHO, 2004, p. 120).

\section{Figura 1 - Mapa de localização de Picos/PI}

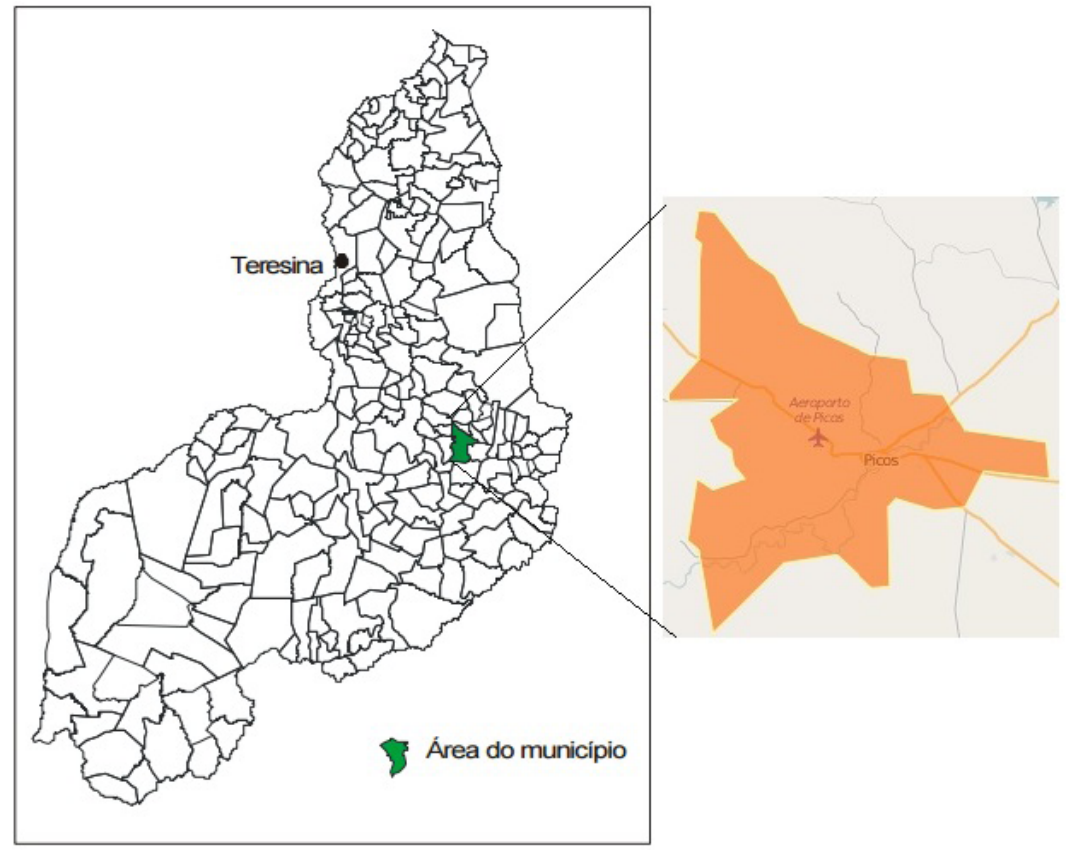

Fonte: http://www.cprm.gov.br/rehi/atlas/piaui/relatorios/157.pdf. (Com adaptações).

A localização sertaneja dessa cidade, no contexto territorial nordestino e piauiense, também responde aos motivos da produção de série de fragilidades ambientais, fato que, a partir da fig. 1, a seguir, nos dá noção ampliada do que narraremos.

$5 \quad \mathrm{Na}$ verdade, é considerado o segundo maior entroncamento rodoviário do Nordeste do Brasil, atravessado pela BR Transamazônica. O de maior envergadura e importância é a cidade de Feira de Santana/BA

6 Tendo como principais mercados, o europeu e americano, a produção de Mel em Picos é uma das maiores do Brasil, tendo como frente de comando desse processo evolutivo, Central de Cooperativas Apícolas do Semiárido Brasileiro Casa Apis. Nesse mesmo encaminhamento é falado também da produção de castanha de caju e derivados, planejado e organizado pela Central de Cooperativas dos Cajucultores do Estado do Piauí - COCAJUPI, tendo como grande parceiro de compras, a Itália. 
Sua localização nos sertões piauienses, dá-lhe tons de conteúdos e condições geoambientais específicos, pois a área urbana em apreço e suas adjacências fazem-se caracterizadas por apresentarem, além de solos rasos e jovens, também um relevo modelado em rochas sedimentares argilo-arenosa "com topografia suavemente ondulada a plana, dissecada e formas tabulares, vales e testemunhos, caracterizando quatro aspectos geomorfológicos distintos: zonas de chapadas, zona de testemunhos, zona de dissecação e aluviões" (LIMA, 1982).

Associada e complementando esse quadro fisiográfico, diz-se que as condições climáticas de Picos/PI, sediado a $190 \mathrm{~m}$ acima do nível do mar, marcam-se por "temperaturas mínimas de $22^{\circ} \mathrm{C}$ e máximas de $39^{\circ} \mathrm{C}$, com clima semiúmido e quente. Ocasionalmente, chuvas intensas, com máximas em 24 horas (AGUIAR \& GOMES, 2004, p.03). Pois dado o fato de ser uma cidade cravada em ambiência sertaneja, seu conteúdo ambiental, por tendência natural, é frágil.

Considerando o fato de ser cercada por muitos morros, há sobre estes, uma forte dinâmica imobiliária de ocupação, permitindo às classes sociais da cidade mais pobres, processos de ocupação desordenado e sem planejamento, o que repercute em novas condições paisagísticas na cidade (maior parte negativa!). Nos espaços de superfície plana, há, também, uma forte tecnificação do espaço, que colabora na obstrução e ocupação desordenada de trechos do Rio Guaribas ${ }^{7}$. Associada à questão da distribuição e ocupação irregular das moradias, sobre os modelados terrestres que entrecruzam o sitio urbano, destacam-se práticas de escavamentos dos sopés dos mesmos, com a retirada de materiais para fins comerciais, destacando-se ai a remoção da cobertura vegetal de forma expressiva.

Deste conjunto de condições sobre a espacialidade urbana na cidade de Picos, notadamente sobre suas paisagens e conteúdos (ambientais e sociais), vê-se, então, que essas condições resultam de uma ciranda de ações engendradas espacialmente a partir dos processos de produção capitalista, notadamente, as reveladas pelo fator imobiliário que se faz em ascendência e expansão.

Por meio desses procesos há uma exaltação para o crescimento desordenado da cidade, oportunidade que Aquino e Veloso Filho (2000) atestam que este crescimento revela uma nova condição e composição que desembocam em uma alteração paisagística, entre outras, revelada pela "ocupação das margens do rio em desrespeito aos limites legais da área de preservação permanente, aumenta a incidência de esgotos e lixo a serem lançados, acentuando a problemática ambiental no seu perímetro urbano".

Assim, grande parte destas transformações e logicamente, a promoção de cenários de riscos e vulnerabilidades socioambientais na cidade de Picos/PI estão "relacionadas às cheias, a mudança no curso do rio, a construção de rodovias federais e estaduais, às elevações geomorfológicas que ficam no entorno do centro urbano, com casas espalhadas pelas encostas de morros [...]" (SOUSA; ARAGÃO, 2012).

O dinamismo econômico e produtivo assumido por esta cidade e seu posterior raio de influência ampliado a um grande número cidades, dentro do quadrante popular conhecido como "macroregião de Picos" 8 também é repercutido negativamente no interior da região, considerando os fatores mobilidades e tráfego, pois são nítidos um avolumado conjunto de problemáticas sociais e até ambientais, considerando a ausência/deficiência na existência e expansão de infraestruturas tão necessárias ao "desenvolvimento das atividades político administrativas, entre os quais se inclui a gerência da própria cidade" (NETO, 1997, p. 40).

É este gerenciamento tão necessário à minimização das problemáticas urbanas que quando mal executado permite o recrudescimento de sérios problemas, a exemplo de uma "grande pressão

7 Principal rio da Bacia que tomam o mesmo nome. "Corta" a cidade de Picos/PI e já foi motivo e sinônimo, em tempos pretéritos, de progresso para todo o vale do qual banha, a partir da produção de alho, hoje, falida.

8 Refere-se ao raio de influência e comando regional que Picos/PI tem sobre mais de trinta cidades, inclusive agregando cidades do estado do Ceará e Pernambuco adjacentes. 
social com relação a problemas de moradia, com o surgimento de favelas, cortiços, loteamentos clandestinos em áreas de preservação ambiental, habitações ilegais [...]” (NOBREGA, 2013, p. 24). Dessa forma, sobre a cidade de Picos/PI tais problemas vêm avolumando.

Pensando dessa forma e como tentativa de uma ampliação de esforço teórico para compreensão das transformações urbanas sertanejas do Piauí que explicitem a promoção da produção de riscos e vulnerabilidades socioambientais, particularmente, em Picos/PI, destaca-se a constituição do conceito de Dinâmicas Urbanas em Espaços Sertanejos Piauienses (DUESPI).

A composição de uma nova modalidade conceitual para estas realidades de transformações urbanas, localizadas em espaços sertanejos do Piauí, não tenciona ser uma totalidade fechada de compreensões sobre tais dinâmicas, já que elas ocorrem e diferenciam-se quer numérico e ou qualitativamente entre as diferentes cidades, mas deseja apresentar como um "instrumento metodológico do conhecimento que expressa a essência do objeto; essência esta que, no caso tratado, revela as leis de movimento de uma realidade regional: sua origem, desenvolvimento e, eventualmente, seu desaparecimento" (BREITBACH, 1988, p. 11).

Pensando dessa forma é que se reconhece o papel das ciências no processo mobilizatório na produção dos conhecimentos: o de desvendar o mundo, explicitando o conteúdo, organização e rebatimentos de seus fenômenos, nas diferentes escalas espaciais, oportunidade em que é possível "ler" as diversas realidades que se materializam nos diversos lugares.

É nessa possibilidade que as diversas "leituras" em destaque são permitidas pelas ações empíricas de análise, momento em que os objetos de estudos conseguem transmitir impressões (geralmente superficiais), que muitas vezes não conseguem dar respostas precisas e definidas acerca do que se espera obter de respostas no processo investigativo sobre os objetos investigados.

É aí que as ciências, via arranjos metodológicos e instrumentais de trabalho conseguem ratificar e ou negar o que fora pensado em termos hipotéticos construídos no processo investigativo em que o sujeito pesquisador se propõe a fazer. Assim, na relação empiricista e metodológica há sempre a possibilidade conectiva entre os elementos do "real e ao mesmo tempo, a essência do objeto e a sua manifestação: entre elas há uma relação íntima, necessária e contraditória, cabendo à ciência desvendar essa relação" (Idem, 1988, p. 20).

Nesse ínterim de movimentações da relação em apreço, é que surge então a formulação de CONCEITOS, cuja possibilidade "significa dizer que se teve acesso à essência do objeto, a partir do que podem ser percebidas as leis de movimento do real, seus desdobramentos, sua estrutura interna" (Ibidem, 1988, p. 21).

Este esforço permite e induz-nos a uma maior capacidade de "leituras espaciais". Muitas destas, amparadas em visões ideológicas, permite enxergar o espaço urbano para além de suas fragmentações, mas também em sua totalidade, já que a constituição e organização destes espaços é a que "reúne a todos, com suas diferenças, suas possibilidades diferentes de uso do espaço relacionados com possibilidades diferentes de uso do tempo" (SANTOS, 1997, p. 31).

$\mathrm{Na}$ promoção do conceito em evidência, consideramos a existência de "elementos" e "variáveis", exposta logo abaixo. 


\section{Tabela 1 - Elementos e Variáveis na composição das Dinâmicas Urbanas em Espaços Sertanejos Piauiense}

\section{Elementos e variáveis na composição das Dinâmicas Urbanas em Espaços Sertanejos Piauienses}

Elementos

População

Economia

Atrativos/condições infraestruturais

Dinâmica imobiliária

\section{Variáveis}

Êxodo rural; Migrações/mobilidade intramunicipal.

Novos equipamentos comerciais/serviços;

Novos investimentos/investidores.

Políticas públicas; Parcerias publico/privada.

Agentes Produtores do Espaço Urbano.

Fonte: LIMA (2014).

Observa-se que os elementos e variáveis pensados para a construção do conceito proposto é além de complementares, dinâmicos, considerando a perspectiva de sua continua reorganização e localização sobre os diferentes recortes do espaço intraurbano. Esquematicamente por meio do organograma 1 abaixo, é possível visualizar o corpo de composição dos itens descritos anteriormente e sua respectiva ligação.

\section{Organograma 1 - Elementos e variáveis para Dinâmicas Urbanas em Espaços Sertanejos Piauienses (DUESPI).}

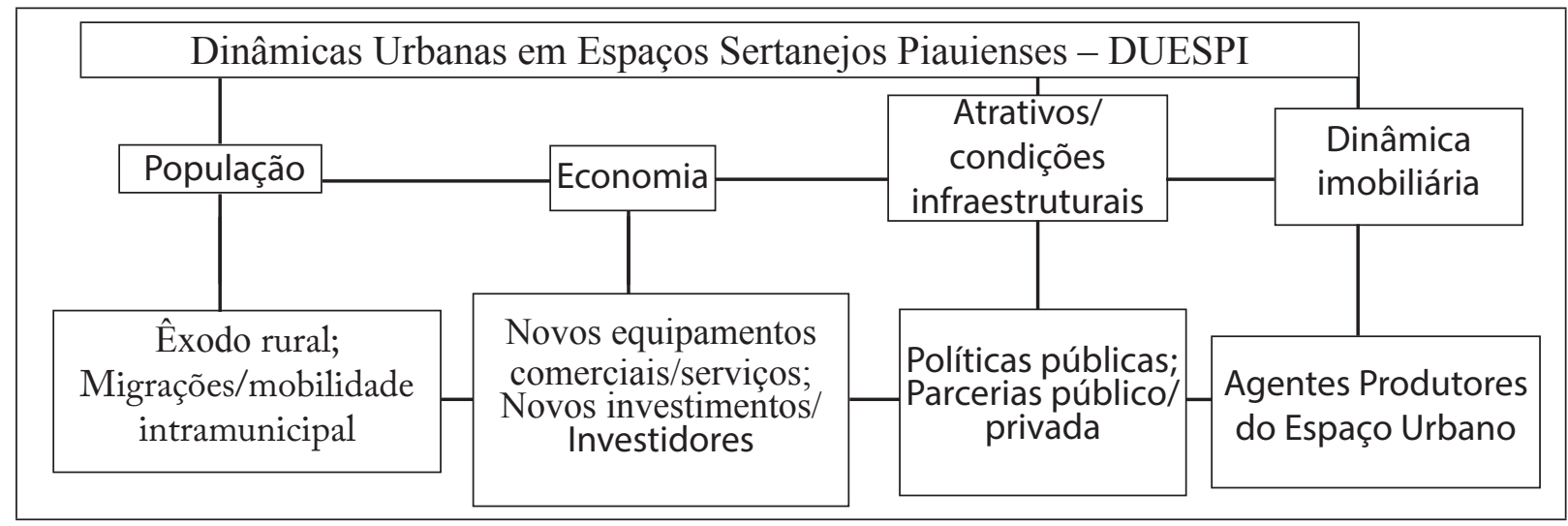

Fonte: LIMA (2014).

A partir da construção exposta e considerando o entrelaçar dos elementos e variáveis envolvidos ${ }^{9}$, entende-se por Dinâmicas Urbanas em Espaços Sertanejos Piauienses (DUESPI), o "conjunto de transformações aos quais estão submetidas as várias cidades sertanejas piauienses inseridas dentro de uma lógica de transformações infraestruturais, sociais e econômicas impulsionadas pela recente lógica de expansão e desconcentração de atividades econômicas/produtivas no Brasil”.

9 Dada a dinâmica comercial e de serviços em Picos/PI, os elementos economia e atrativos/condições infraestuturais, ano após ano fazem-se diversos e amplos. Nesse contexto, há uma concentração dos mesmos, seja na extensão da BR 316 (Transamazônica), que "corta" o interior da urbe, bem como no centro. Nessa possibilidade, o trabalho dos Agentes Produtores do Espaço Urbano concentra-se nos esforços da constante valorização do solo urbano voltado para essas atividades. Soma-se a esse fato, a concentração de ensino básico e universitário, oportunidade que convida anualmente, uma grande quantidade de alunos e profissionais, momento da busca de imóveis para moradia e com isso, a ciranda de expansão de construções verticalizadas. Nesse momento, as áreas de expansão para essa perspectiva são agraciadas com certa dose infraestrutural, estando os bairros mais antigos ou em encostas de morros ou ainda, áreas de recepção e acumulação de águas, bem como, os variados vazios urbanos, com expectativas de ocupação, desassistidos de políticas de reordenamento urbano e ou infraestruturas/condições que minimizem a produção de espaços e condições de vulnerabilidades socioambientais e riscos. 
Norteiam-se ai as condições, via elementos e variáveis na ampliação e dinâmica de transformações da malha urbana de Picos/PI, permitida pela expansão e seletividade imobiliária que entre outras possibilidades, influi para ocupações urbanas desordenadas, fruto das dinâmicas de expansão descontroladas. Estas, para Jacobi (2004), consistem em habitações pobres em áreas com escassos serviços urbanos. Contêm nesse sentido, características inerentes para as diferentes realidades encontradas em Picos/PI.

Nesse direcionamento, as condições provocadoras das vulnerabilidades socioambientais, indutoras da promoção de riscos revelam comportamento dos sistemas naturais da/na cidade, resultantes a partir das ações impactantes que se dão sobre o seu "quadro natural que apresenta uma vulnerabilidade acentuada pela intensa pressão demográfica e por fatores diretamente vinculados ao rio Guaribas" (FILHO, 2004, p.110).

Uma das primeiras manifestações de produção de riscos e vulnerabilidades na cidade é apresentada logo abaixo, nas figuras 2 "a" e "b", logo abaixo. Fig. 2 "a" - Deslizamento de massa em área de ocupação. Fig. 2 "b”
- Ocupação desordenada/condições de riscos.

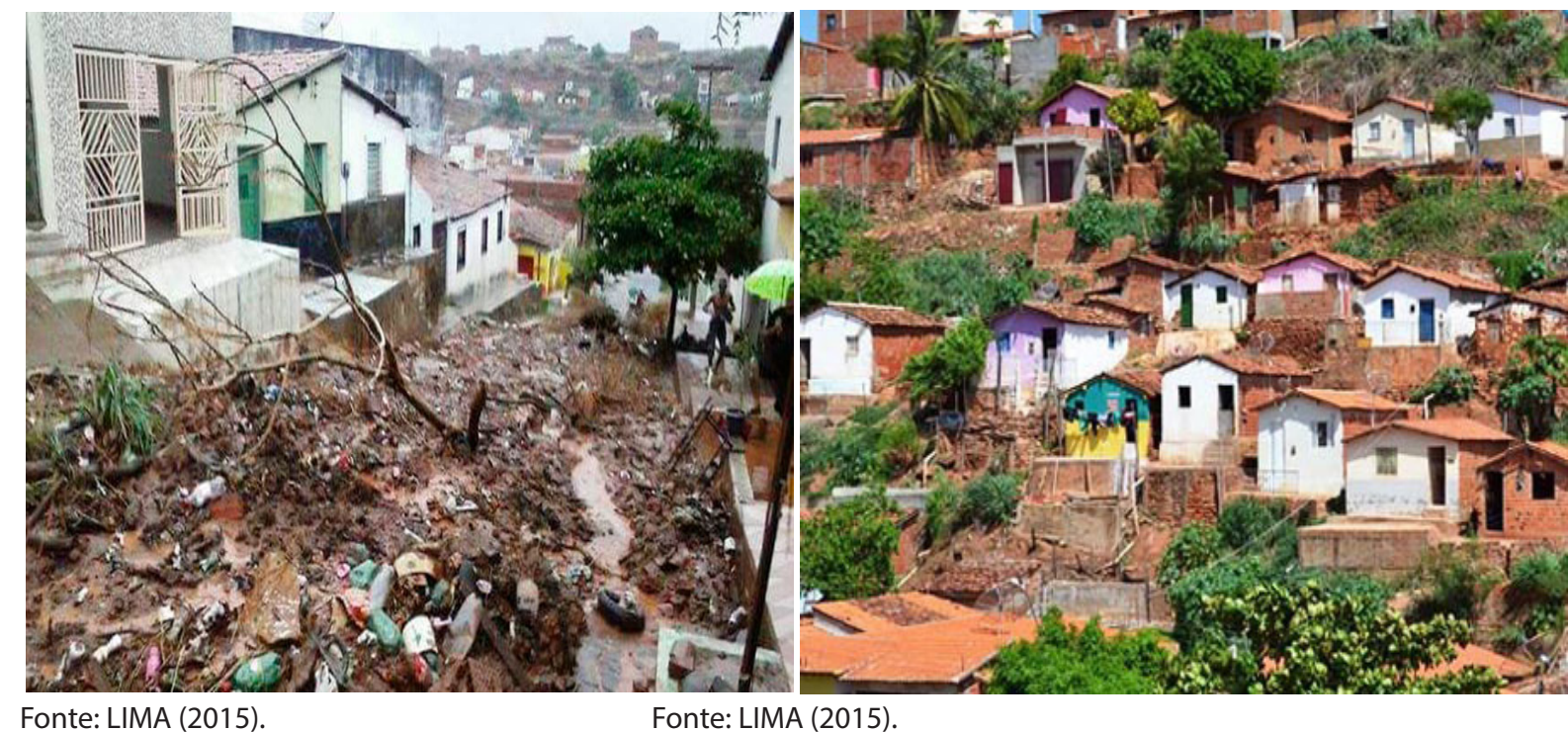

Nas figuras 3 "a" e "b", a seguir, exemplo de empreendimentos imobiliários que denotam status, valorização da área localizada e condição de segregação social, um dos atributos de promoção de vulnerabilidades. Estas construções foram concretizadas em espaços de ocupação de topografia irregular, oportunidade em houvera necessidade de intervenções de engenharia, resultando no barramento de córregos e áreas de acumulação de água até então existentes (Bairros Ipueiras e Alta Mira, respectivamente). 


\section{Fig. 3 "a" - Conjunto residencial planejado. Fig. 3 "b" - Santiago Residence Condomínio

\author{
de luxo.
}
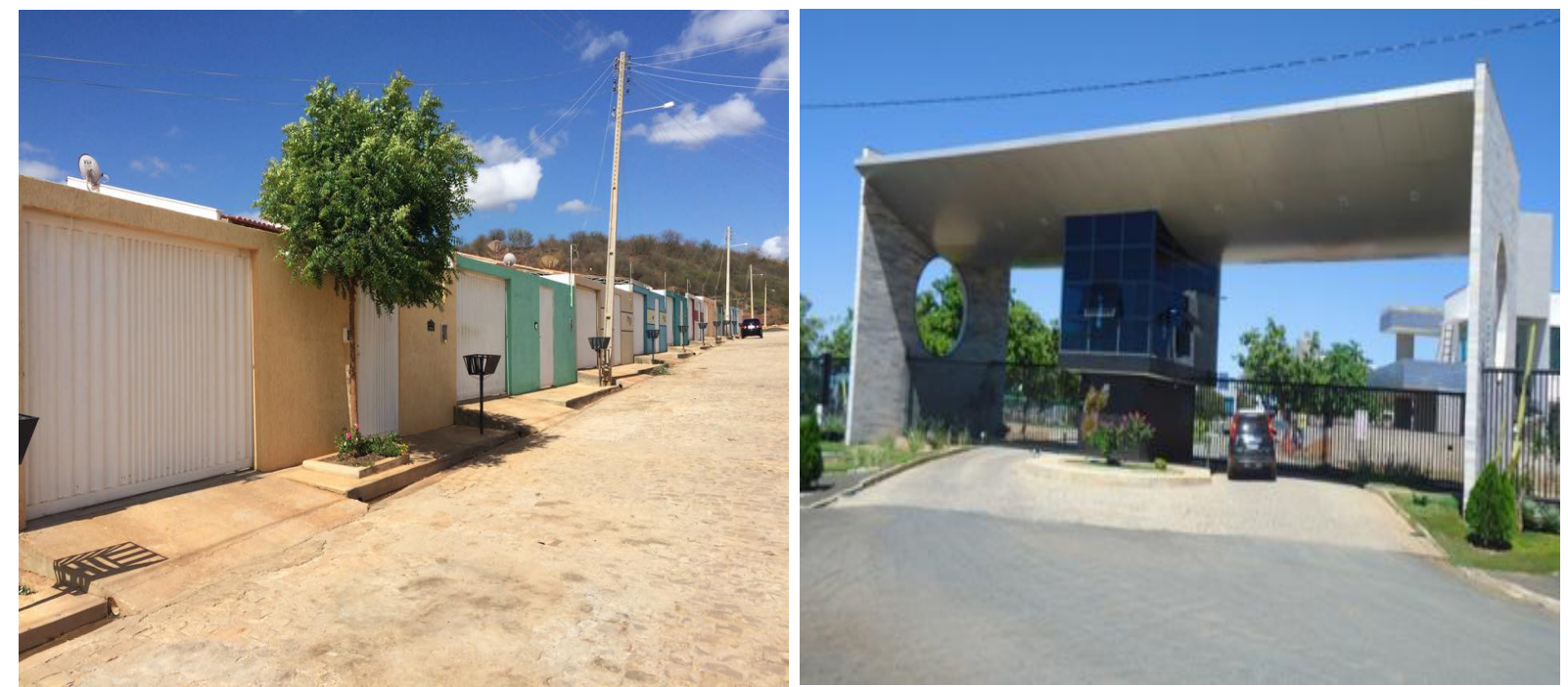

Fonte: LIMA (2015).

Fonte: LIMA (2015).

Vê-se ai a heterogeneização da composição social e paisagística, a partir do setor imobiliário. Este, dinamicamente trabalha com várias ações para o aprofundamento das referidas composições. Dessa forma, investe nesse processo, a constituição em maior e ou menor escala os grupos sociais de maior renda ocupando os "ambientes de amenidades sociais e ambientais e com melhor infraestrutura e serviços, enquanto os de menor poder aquisitivo, os mais vulneráveis, tendem a localizarem-se nas chamadas áreas de risco, ou seja, áreas de maior exposição a situações insalubres” (ZANELLA, et al, 2009, pag. 193).

Colabora para novas condições paisagísticas na cidade (maior parte negativa!), além das inúmeras edificações em espaços margeadores do Rio Guaribas, também a forte tecnificação nas adjacências do mesmo. Ampliam ainda a questão, a distribuição e ocupação irregular das moradias sobre os modelados terrestres que entrecruzam o sitio urbano. Sobre estes, há, ainda, a prática de escavamentos com a retirada de materiais para fins comerciais, destacando-se ai a remoção da cobertura vegetal de forma expressiva.

A expansão urbana,impulsionada pela dinâmica imobiliária e o (des) ordenamento espacial, comandado por este setor e atividades comerciais e serviços fortemente tem mudado a feição paisagística da cidade. $O$ constante rearranjo espacial, por meio de seus conteúdos "sintetizam todas as funções e os conhecimentos para a composição dos espaços.” (BONAMETTI, 2010, p. 263).

Nesse sentido, as transformações no espaço urbano de Picos/PI, notadamente sobre suas paisagens e conteúdos, perfazem uma ciranda de condições que resultam dos processos de produção capitalista. Comprova esse processo, a visualização das figuras 4 "a" e "b" a seguir. 
Fig. 4 "a" - Transbordar do Rio Guaribas. Fig. 4 "b" - Alagamento em área de ocupação desordenada.

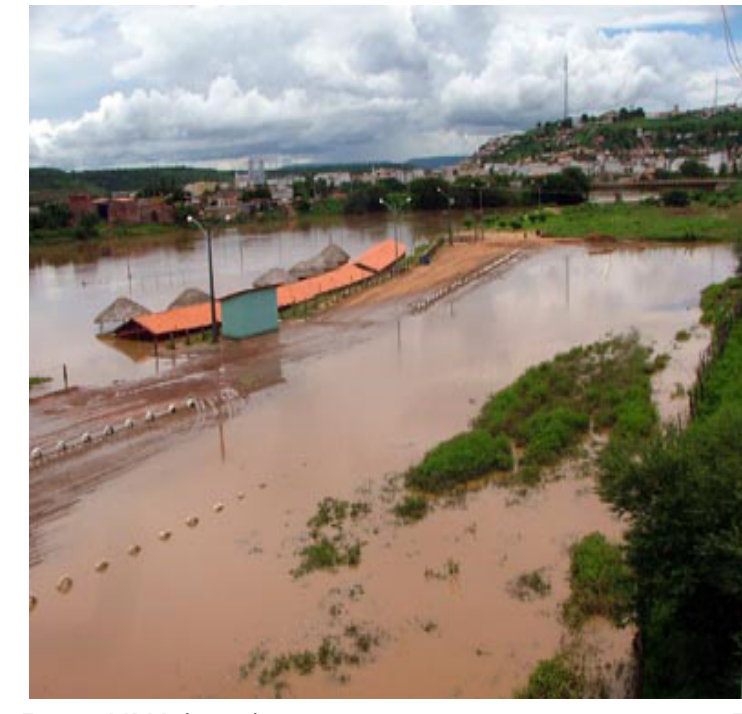

Fonte: LIMA (2015).

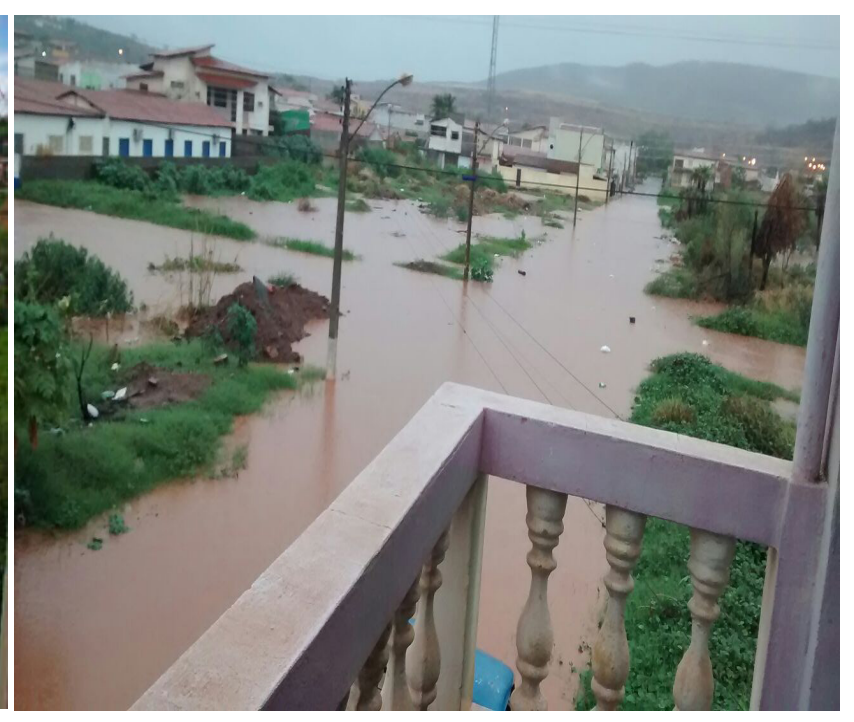

Fonte: LIMA (2015).

É evidente aí, via sociedade urbana em progresso material, sinonimamente travestida de um errôneo sentido de um desenvolvimento local e também regional, elementos no constructo de diferentes relações nos processos de produção do espaço, onde o ambiente construído e natural "adquirem uma importância cada vez maior, destacando a natureza como recurso e como valor de uso, reforçando os ambientes naturais como valor para a produção de um novo espaço, transformando-os em áreas urbanizáveis" (NELBA AZEVEDO PENNA, 2002, p. 35).

Por fim e não menos importante, a realidade já apontada anteriormente e, que impõe sobre a cidade de Picos, uma das principais facetas negativas concernentemente a promoção de problemáticas ambientais é a da qualidade de suas vias de circulação, haja vista o intensivo transito permitido por sua dinâmica de comando regional, via um significativo número de uma população flutuante diária que entra e sai da cidade, conforme é atestado nas figuras 5 "a" e "b".

\section{Fig. 5 "a" - Raio X do trânsito em Picos/PI. Fig. 5 "b" - Retrato das condições das vias em Picos/PI}

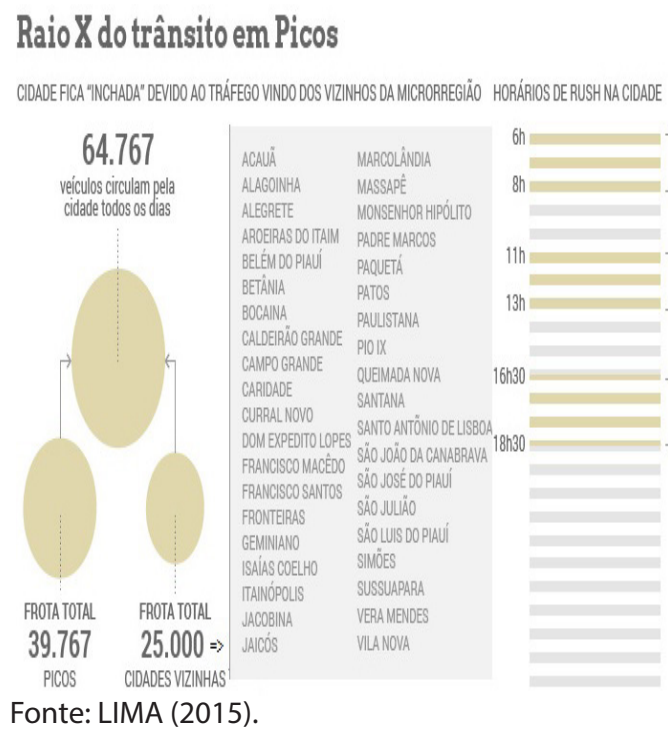

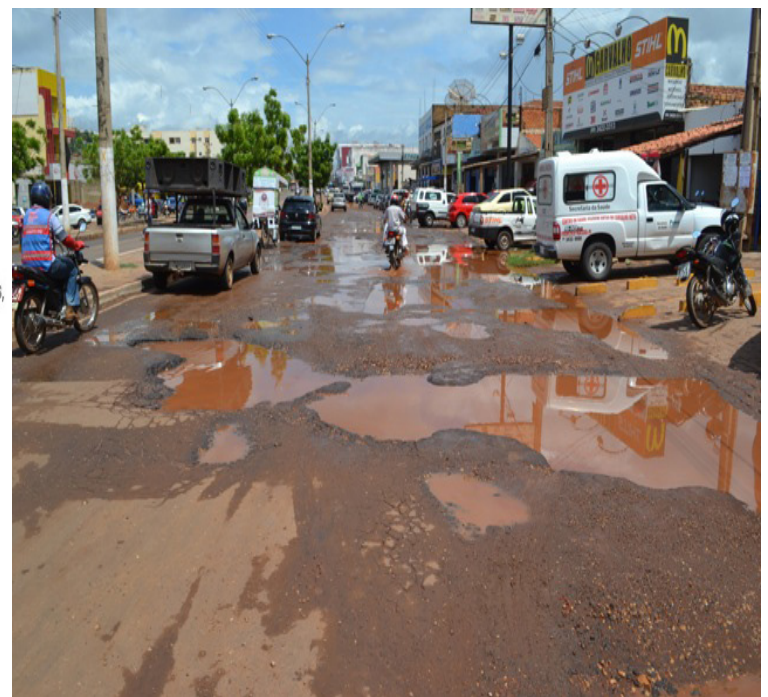

Fonte: http://g1.globo.com/brasil/caminhos-do-brasil-caravana-g1/ picos/platb/ 


\section{Considerações Finais}

Dada as acumuladas transformações na cidade de Picos/PI, é visível e incongruente o crescimento desordenado e sem planejamento mesma, já que se trata de uma das maiores expressividades urbanas no estado do Piauí em termos de PIB e que ano após ano tem recebido um número crescente de empresas com ofertar de serviços diversificados.

Salienta-se a ausência de políticas públicas e de ações de reordenamento territorial, notadamente, as que versam sobre a necessidade de resolução da realidade de expansão urbana descrita, bem como da ampliação da produção de áreas de vulnerabilidades socioambientais e as de riscos já mostradas. Nesse encaminhamento, dada a condição de uma cidade de poder e comando regional, Picos/PI, tem na atividade imobiliária o principal mote para explicação dos processos de produção de vulnerabilidade em destaque e produção de áreas de risco.

A exposição da formulação do conceito descrito e sua aplicação para compreensão do que aqui foi proposto, além das maturações postas e, considerando a realidade urbana descrita, permitiu o vislumbramento das dinâmicas de ações para a ocupação desordenada e sem limites sobre pontos específicos da cidade, oportunidade que amplia visualização de pobrezas, desigualdades e a emergência de vulnerabilidades socioambientais, com destaque, para os bairros Morada do Sol, Aerolândia, Cidade de Deus, Chão dos Padres, entre outros.

Outra visualização notória é a falta de educação ambiental por parte da população, uma vez que entulhos, lixos e vários materiais descartáveis são lançados às margens e extensão do Rio Guaribas. Sobre este recurso hídrico, destacam-se áreas/espaços na cidade que contém pequenos riachos e lagoas, receptoras de águas do rio em tela, estão praticamente todos soterrados, quer seja pelos fatores já mencionados acima, resultados de uma dinâmica capitalista de transformação do espaço, quer seja também, pela falta de sensibilidade da população com referência ao descarte de resíduos/entulhos, bem como da ausência do gestor munícipe em efetivar políticas de conscientização ambiental.

Por fim, cita-se o caso que está a "estrangular" a qualidade de vida e ambiental na cidade que são as condições péssimas das vias de circulação que quando associada à ideia de que Picos/ PI é o segundo maior entrocamento rodoviário do Nordeste, então a problemática tende a ser ampliada. Considere que dada a polarização desta cidade sobre trinta e nove municípios ao seu redor, (incluindo algumas cidades dos estados de Pernambuco e Ceará), o quantitativo populacional é diariamente ampliado vertiginosamente. Pesquisa de campo via entrevistas colheram informações de que na cidade entram diuturnamente 97 veículos regularizados e mais de 150 clandestinos de transportes que trazem diariamente cerca de 20 mil pessoas ao município para a realização de atividades diversas, com destaque para consumo no comércio.

\section{Referências}

AGUIAR, R.B; GOMES, J.R.C. Projeto Cadastro de Fontes de Abastecimento por Água Subterrânea. Estado do Piauí: Diagnóstico do Município de Picos. Disponível em: <http:// www.cprm.gov.br/>. Acesso em: 22 set. 2012. 
ALMEIDA, L. Q. Riscos ambientais e vulnerabilidades nas cidades brasileiras: conceitos, metodologias e aplicações. São Paulo: Cultura Acadêmica / UNESP, 2012.v.1.

Por que as cidades são vulneráveis. Revista da Casa da Geografia de Sobral, Sobral, v. 13, p. 70-82, 2011.

AMORIM FILHO, Oswaldo; SERRA, Rodrigo Valente. Evolução e perspectivas do papel das cidades médias no planejamento urbano e regional. In: ANDRADE, Thompson Almeida; SERRA, Rodrigo Valente. (Orgs.). Cidades médias brasileiras. Rio de Janeiro: IPEA, 2001.

AQUINO, C. M. S.; VELOSO FILHO, F. A. Diagnóstico sócio-ambiental da cidade de Picos-PI. Teresina: UFPI/TROPEN/WAVES, 2000. (Relatório Técnico).

ARAUJO, Tarcisio Patricio de. Nordeste: economia e mercado de trabalho. Estudos Avançados, São Paulo, v. 11, n.29, p. 55-77, 1997.

BALL, M. Differential rent and the role of landed property. International Journal of Urban and Regional Research. London: Edward Arnold, p. 380- 403, 1977.

BONAMETTI,J. H.. Paisagem Urbana e Poder. URBE - Revista Brasileira de Gestão Urbana, Curitiba, v. 2, p. 259-273, 2010.

BREITBACH,Á. C.M. . Notas sobre a importância metodológica dos conceitos. Ensaios FEE, Porto Alegre, v. 9, n.1, p. 121-125, 1988.

DESCHAMPS, M.V. . Vulnerabilidade Sócioambiental na Região Metropolitana de Curitiba. Tese de Doutorado em Meio Ambiente e Desenvolvimento. Programa MADE. Universidade Federal do Paraná, Curitiba, 2004.

DUBOIS-MAURY,J.; CHALINE, C. Les risques urbains. Paris: Armand Colin, 2004.

FAÇANHA, Antônio Cardoso. A Evolução Urbana de Teresina: Agentes, Processos e Formas Espaciais da Cidade. Dissertação de Mestrado - Programa de Pós Graduação e Geografia da Universidade Federal de Pernambuco - UFPE, Recife, 1998.

FILHO, João Soares da Silva. Indicadores de Desenvolvimento Sustentável nos municípios da Bacia Hidrográfica do Rio Guaribas - Piauí. Dissertação de Mestrado - Programa Regional de Pós Graduação em Desenvolvimento e Meio Ambiente da Universidade Federal do Piauí (PRODEMA/UFPI/TROPEN) - UFPI, Teresina, 2004.

FREITAS, M.I.C.; CUNHA, L. J. S. . Cartografia da Vulnerabilidade Socioambiental: Convergências e Divergências a Partir de Algumas Experiências em Portugal e no Brasil. Revista Brasileira de Gestão Urbana, v. 5, p. 15-31, 2013. 
GRAZIA, Grazia de, QUEIROZ, Leda Lúcia R. F. et al. O desafio da sustentabilidade urbana. Projeto Brasil sustentável e democrático-FASE/IBASE, Rio de Janeiro, 2001, 128 p. (Série Cadernos Temáticos, n 5).

JACOBI, Pedro. Impactos Sócioambientais urbanos - do risco à busca da sustentabilidade. MENDONÇA, F. (org). Impactos Socioambientais Urbanos. Curitiba: Editora UFPR, 2004, 328 p.

LIMA, I. M. de M. Fé. Caracterização geomorfológica da bacia hidrográfica do Poti. Dissertação de Mestrado - Programa de Pós Graduação em Geografia. Instituto de Geociências - UFRJ, Rio de Janeiro, 1982.

LIMA, Juscelino Gomes. Dinâmicas Urbanas em Espaços Sertanejos Cearenses (DUESC): novas configurações do urbanos e ações imobiliárias em Sobral/CE. Dissertação de Mestrado. Programa de Pós Graduação em Geografia. Universidade Estadual Vale do Acaraú - UVA. Sobral, 2014.

LIPIETZ, A. Le tribut foncier urbain. Paris: Maspero, 1974.

MENDONCA, F. A. Riscos, vulnerabilidade e abordagem socioambiental urbana: Uma reflexão a partir da RMC e de Curitiba. Desenvolvimento e Meio Ambiente (UFPR), Curitiba, v. 1, p. 139-148, 2005.

. ; LEITAO, S. A. M. . Riscos e vulnerabilidade socioambiental urbana: Uma perspectiva a partir dos recursos hídricos. Geotextos, Salvador, v. 4, p. 145-163, 2008.

Nelba Azevedo Penna. Urbanização, Cidade e Meio Ambiente. Geousp, São Paulo, v. 12, n.1, p. 34-51, 2002.

NETO, W. Z. 1997. Infra-Estrutura Urbana. Disponível em: <http://pcc2561.pcc.usp. br/ttinfraestrutura17.pdf>. Acesso em: 26 set. 2014.

NOBREGA, Fábio Augusto Rodrigues da. Infraestrutura urbana: infraestrutura e o crescimento populacional no Brasil. Cadernos de Graduação - Ciências Exatas e Tecnológicas, Sergipe, v.1, n 16, p. 19-25, 2013.

REBELO, F. Geografia física e riscos naturais. Coimbra: Imprensa da Universidade de Coimbra, 2010.

ROSS, Jurandyr Luciano Sanches. A Sociedade Industrial e o Ambiente. Geografia do Brasil. Ross, Jurandyr Luciano Sanches (Org.). São Paulo: EDUSP, 1998.

SALVADOR, D. S. C. O. . A Geografia e o método dialético. Sociedade e Território, Natal: UFRN, v. 24, p. 97-114, 2012. 
SANTOS, Milton. A natureza do espaço: técnica e tempo, razão e emoção. São Paulo: Hucitec, 1997.

A natureza do espaço. São Paulo: Edusp, 2008.

SOUSA, M. V. H. ; ARAGÃO, Juliana Lopes. A cidade em perspectiva: mudanças espaciais e urbanísticas na cidade de Picos (PI) no período de 1960-1980. VI Simpósio Nacional de História Cultural, Teresina, 2012. Anais, v. 1.

TOPALOV, C. Les promoteurs immobiliers. Paris: Mouton, 1974.

ZANELLA, Maria Elisa, et al. Vulnerabilidade socioambiental de Fortaleza. Vulnerabilidade Socioambiental na Região Metropolitana de Fortaleza. Edições UFC: Fortaleza, 2009. 